\title{
A Student Centered Method for Teaching Professional Paper Writing
}

\author{
L. Paul MANTHA*, Zi-qi LIU and Dan-dan WANG
}

Sino-Dutch Biomedical and Information Engineering School of Northeastern University, Shenyang, China

${ }^{*}$ Corresponding author

Keywords: EAP writing, Student centered, Project based learning

\begin{abstract}
Publish or Perish has arrived in China and for students it is more imperative than ever that they learn how to design their own projects and present their research. This paper presents a student centered project based method for teaching professional paper writing. In this course students will conduct two simple experiments and then using an IEEE template to write a paper to present their research. In order to increase student participation the course employs fortnightly tutorials that employ the student's writing as the main text. The first paper is practice as student choose a topic from Game Theory. The Second Paper is production as the topic is chosen by the students. Through the two papers students gain knowledge of both how to develop the different sections of a paper and the appropriate language to use. The paper ends with a discussion of ways to increase the effectiveness of each of critical feedback and the operation of the tutorials.
\end{abstract}

\section{Introduction}

The importance of being able to write a paper that could be published in English cannot be understated in contemporary academia and thus is vital for students to gain knowledge in how to write such a paper. While textbooks exist to teach Professional Paper Writing, they are generally geared to a narrow range of language abilities and thus are of limited use in most classes which have a wide range of language competencies. In addition to the linguistic abilities there also exist argument structure differences between languages such as the Chinese preference for writing in a paratactic circular style with heavy pronoun and verb use versus the English preference for an impersonal hypotactic linear style which relies on abstract nouns. [1] Another problem is that Chinese students are very short term test oriented and thus may view anything that is written or presented as being the final product.

One of the changes in Chinese Higher education is a move towards skills and knowledge [2] based learning as opposed to simple rote memorization. In this paradigm learner autonomy has an increased importance.[2] Research has shown that students are capable of learning from their own errors [3] and that peer feedback provides both a different perspective as well as input that is closer to the learner's level.[4] It has also demonstrated that explanatory feedback is superior to simple error correction or written feedback because the learner can interact and thus make the feedback more understandable.[5,6] This paper presents a teaching method that increases learner autonomy by moving from a guided practice paper to an independently designed one. Employs student writing as the main text and focuses on ways to improve that writing, not just at the word and sentence level but also at all levels above the sentence. And includes explanatory peer and instructor feedback on how to improve their writing.

\section{Teaching Method}

This course is intended to be conducted in one semester with 32 hours of instructional time. There are only three times that the whole class is together: The First Class, Introduction to the Course. The Eight Class, Paper One Presentations and the Last Class, Paper Two Presentations. For the remained of the classes a one hour fortnightly tutorial is employed. The class is divided into groups with two or three 
teams of three in each group. This allows for all members of a group to read what the other teams have done and be able to provide constructive feedback.

\section{Presentation}

The Introductory Class begins with a demonstration experiment from Game Theory. Rock, Paper, Scissors was chosen as all students are familiar with it. To start the Instructor uses gestures to translate the Rock, Paper, and Scissors. The students are then told that a Rock, Paper, Scissors tournament will be played. A chart is written on the board and a volunteer selected to record the data. Eight pairs of students are then chosen to play a game with the winner moving to the front of the class. Elimination rounds are then played until there is only one student remaining, who is declared the winner. The students are then asked what is required to publish a paper on the experiment. With reference to Rock, Paper Scissors all the sections of a professional paper start with Introduction followed by Method, Results and Discussion are explained. While the Abstract goes first, here it is presented last because it is a summary of the paper and better understood after the other sections have been discussed.

\section{Practice: Paper One}

Students are given a website with a list of games from Game Theory [7]. Told to form teams of three and chose a game. They are also instructed to be ready to introduce their game in the First Tutorial and discuss how they plan to do the experiment. A brief summary of each section is provided. A feedback form (see Appendix 1) is provided and students are informed they will be required to use the form during every tutorial.

\section{Paper One, Tutorial One}

Students introduce their "Game", the other groups are asked if they understood and if they have any questions about the game. The feedback form is shown to the tutorial and students are asked if the introduction covered all the areas of the feedback and if anything could make the Introduction better. The Instructor then provides feedback by asking questions and when needed reviewing the function of an Introduction.

In the next part, students describe how they intend to do the experiment. As the focus of the course is on writing, the Instructor provides ideas that may help in completing the experiment faster. In order to assist in understanding how to write a methods section a simple cooking recipe (method) is shown. Stress is placed upon the idea that anyone who reads the recipe has enough information to do the same thing. Students are instructed to write both the Method and Results sections, make a two printed copies and to read the other groups papers before the next tutorial.

\section{Paper One, Tutorial Two}

All teams hand the Instructor a printed copy of their paper sections, they retain the other printed copy for notes. The teams take turns presenting their work and providing feedback. While they are doing this the Instructor listens and only asks questions or rephrases comments to help in intelligibility. Quite often students have trouble communicating ideas in English so the Instructor assists by rephrasing and asking questions. Once the student feedback portion is finished the Instructor provides feedback in the order: Section, Paragraph, Sentence and last vocabulary. On the printed copy the Instructor can provide written examples or changes to the oral feedback that is being provided. This is done for two reasons, first it has been found that students often do not understand written feedback, thus by writing, explaining and orally checking comprehension the feedback might become more intelligible and useful' second, it provides a record that students can use after class when they are editing. In the next segment of the tutorial the Instructor explains the functions of the Discussion and Abstract Sections of a paper. The class ends with the students being assigned to finish all sections of the paper, make two printed copies and read each other's work. 


\section{Paper One, Tutorial Three}

All teams hand the Instructor a printed copy of their paper. The teams present their Discussion section and receive feedback before presenting their Abstracts, thus allowing for all section to be discussed before the Abstract. During the peer feedback the Instructor provides only assistance if needed. After all the teams have finished, the Instructor provides feedback on the Discussion and Abstract. Next the instructor asks a series of questions related to the paper as a whole focusing specifically upon the Introduction and the Discussion. As all teams have read all the papers for the tutorial the questions can be asked to the students in general and can be answered by anyone not just the team whose paper is the focus at the time of the question. The tutorial ends with the Instructor providing some suggestions for how to make the paper better, and reminding the students that they have to submit and present their paper in the next class. They also have to prepare a half page proposal for their next paper.

\section{Presentation One}

Whenever students work in groups it common for one or two to do all the work and some to do nothing. The oral presentation is designed to help differentiate the marks between those groups. Students who have done the work tend to present without paper in hand and also tend to look at their classmates more as they know what they are talking about and are capable of answering a few questions, whereas those who have done little or nothing tend to read from the printed work and are incapable of answering questions. Each team presents their paper with the help of a PowerPoint and the Instructor asks a few questions.

\section{Production: Paper Two}

After all the presentations are finished, the Instructor then reviews proposals for the student's next experiment. The main focus of this is to ensure that the students have considered the amount of time they require to do the experiment and whether or not they have given any though in how they are going to do it.

\section{Paper One, Tutorial One}

All teams hand the Instructor a printed copy of their paper. The teams present their Introduction section and receive feedback. The Instructor provides more detailed feedback about the structure, going from general to this paper, as well as background and context building for the experiment and then focuses on the research question. Next each team outlines how they are going to conduct their experiment and receive both peer and Instructor feedback. For the next tutorial students are to revise their Introductions, write their Method and create needed graphs or charts for their Results section. They are also required to read each other's work and to be prepared to help make the other team's work better in the next tutorial.

\section{Paper One, Tutorial Two}

All teams hand the Instructor a printed copy of their paper. The teams present their Introduction and Method sections and receive peer feedback. The Instructor then provides feedback on the sections and also on how the two sections work together. The teams then present their rough Results, the charts or graphs, and orally describe them. After peer and Instructor feedback the teams describe how they are going to write the Discussion section. For the next Tutorial the completed paper must be printed and read by all teams.

\section{Paper One, Tutorial Three}

All teams hand the Instructor a printed copy of their paper. The teams present their Discussion and Abstract sections and receive feedback. The Instructor provides feedback on the Discussion section then uses the Feedback Form to ask questions about the papers as a whole. In the last part of the 
tutorial the Instructor provides suggestions on grammar. Students are to revise the paper and prepare to present in the final class.

\section{Presentation Two}

This is the second chance to differentiate team members. All teams present and hand in their Second Paper.

\section{Discussion}

The majority of students will not create a connection between the writing of these papers and the future writing needs in their major, thus the Instructor must make the connection between the writing needs of these papers and the future explicit. A comparison between the section that is being examined and the student's major is very useful. Creating the connection may also increase student interest and motivation. The most common pronouns in student writing are "I" and "We", ban them and students are forced to find alternative ways to express the same idea, this provides an opportunity for the Instructor to provide suggests and a few sample rewrites. In the second paper student should be a very wide latitude in choosing their topic, bound only by time constrains.

\section{References}

[1] Aiju Yu, Analysis of the Problems of the Chinese College Students' EFL Classroom Writings International Education Studies; Vol. 5, No. 5; 2012

[2] Junhong Ren, Na Wang A Survey on College English Writing in China: A Cultural Perspective English Language Teaching; Vol. 8, No. 1; 2015

[3] Jinjin Lu, Yingliang Liu, Learner Autonomy as an Element in Chinese Education Reform: A Case of English Language Subject English Language Teaching; Vol. 9, No. 3; 2016

[4] B. Jean Mandernach, Maria Zafonte, and Caroline Taylor Instructional Strategies to Improve College Students' APA Style Writing International Journal of Teaching and Learning in Higher Education, , Volume 27, Number 3, 2016 407-412

[5] L. Paul Mantha, Yan-Yan Yu, Han Van Triest, Increasing the Quality of Peer Feedback in a Professional Writing Course, International Conference on Education and Development (ICED 2016)

[6] Zheng Chun-xian A Study of Peer Error Feedback US-China Foreign Language Vol 5 No 4, Apr 2007

[7] Information on https://en.wikipedia.org/wiki/List_of_games_in_game_theory

\section{Appendix 1 Feedback Form}

Abstract
\begin{tabular}{|l|l|l|}
\hline Provides Clear Idea of all sections of paper & 1 -only parts 5- very clear & \\
\hline Clearly written & $\begin{array}{l}1-\text { Run spell and Grammar Check } 5 \\
\text { very clear }\end{array}$ & \\
Spelling, grammar, style & 1 poor 5- All are clear & \\
\hline $\begin{array}{l}\text { States the purpose, findings, and impact of } \\
\text { the work }\end{array}$ & & \\
\hline
\end{tabular}

\section{Introduction}

\begin{tabular}{|l|l|l|}
\hline Provides Sufficient Context & 1 lacking 5-More than Sufficient & \\
\hline Relevant, does not contain irrelevant or & 1 Lots of Extra 5-Nothing Extra & \\
\hline
\end{tabular}




\begin{tabular}{|l|l|l|}
\hline unnecessary information & & \\
\hline Focus and Justification & 1 Ambiguous 5-Very Clear & \\
\hline Clearly written & 1 Run spell and Grammar Check & \\
Spelling, grammar, style & 5 Very Clear & \\
\hline
\end{tabular}

\section{Method}

\begin{tabular}{|l|l|l|}
\hline Presents clear experimental design & 1 Ambiguous 5-Very Clear & \\
\hline $\begin{array}{l}\text { Gives enough detail for readers to replicate } \\
\text { your work. }\end{array}$ & 1 Wrote Something 5 Enough Detail & \\
\hline $\begin{array}{l}\text { Clearly written } \\
\text { Spelling, grammar, style }\end{array}$ & $\begin{array}{l}\text { 1 Run spell and Grammar Check } \\
5 \text { Very Clear }\end{array}$ & \\
\hline
\end{tabular}

\section{Results}

\begin{tabular}{|l|l|l|}
\hline Objectively Written & 1 Subjective 5 Totally Objective & \\
\hline Clear Charts and Tables & 1 Not sure of reason, hard to read & \\
& -5 Clear and Useful & \\
\hline Describes Charts and Tables & 1 repeats number 5 Focuses on trends & \\
\hline Clearly written & 1 Run spell and Grammar Check & \\
Spelling, grammar, style & 5 Very Clear & \\
\hline
\end{tabular}

\section{Dicussion}

\begin{tabular}{|l|l|l|}
\hline Summarizes findings & 1 very brief 5 Clear summary & \\
\hline Puts findings in Context & 1 no context 5 contextualized & \\
\hline Discusses Implications and limitations & 1 no discussion 5 well developed & \\
\hline Clearly written & 1 Run spell and Grammar Check 5 Very & \\
Spelling, grammar, style & Clear & \\
\hline
\end{tabular}

